\title{
Smoking Cessation in Pulmonary Care Subjects: A Mixed Methods Analysis of Treatment-Seeking Participation and Preferences
}

\author{
Freda Patterson PhD MSc, David S Zaslav, Diana Kolman-Taddeo MD, Hillary Cuesta, \\ Mary Morrison MD, Frank T Leone MD MSc, and Aditi Satti MD
}

\begin{abstract}
BACKGROUND: African-American smokers experience disproportionate COPD morbidity. As a front-line COPD behavioral management strategy, smoking cessation is less prevalent among African-American smokers. Identifying barriers and predictors to smoking cessation in this population is important to bridging this disparity. METHODS: In this study, the predictors of enrollment and attendance to a 3-session urban hospital smoking cessation program were examined. A retrospective chart review was conducted for all pulmonary clinic patients who smoked and were referred to the cessation program between June 2013 and May 2014. Demographic, smoking behavior, cardiopulmonary, and health status variables were extracted $(N=253)$. Second, a qualitative assessment of the beliefs and barriers for smoking cessation and physical activity were examined in a sub-sample of the population $(n=41)$. RESULTS: One-hundred forty-seven of the pulmonary subjects (58\%) enrolled in the cessation program, and 40 attended all sessions $(16 \%$ of the total sample). Participants with COPD (odds ratio $=4.65, P=.030)$, or had a mother who had cancer (odds ratio $=4.49, P=.027$ ), were more likely to attend the program. Qualitatively, pulmonary care patients who wanted to quit smoking and be more physically active cited: strong beliefs about the inability to engage in these behaviors, belief that quitting and increased activity might exacerbate poor health, and an inability to obtain pharmacotherapy as barriers to adopting these behaviors. CONCLUSIONS: Smoking cessation program attendance in this sample of mostly African-American smokers was poor. Increased knowledge about cessation benefits and access to full-course pharmacotherapy, particularly in those without a COPD diagnosis and who do not have a maternal history of cancer, may be high-priority targets to promote cessation program uptake in this population. Increased knowledge and access to safe forms of physical activity may also be beneficial. Key words: smoking cessation; COPD; pulmonary care; physical activity; prevention; mixed methods. [Respir Care 2017;62(2):179-192. () 2017 Daedalus Enterprises]
\end{abstract}

\section{Introduction}

COPD is a progressive disease characterized by air-flow limitation that is not fully reversible and includes the con-

Dr Patterson is affiliated with the Center of Biomedical Research Excellence (COBRE) in Cardiovascular Health and the Department of Behavioral Health and Nutrition, University of Delaware, Newark, Delaware. Mr Zaslav is affiliated with the Treatment Research Institute, Philadelphia, Pennsylvania. Drs Kolman-Taddeo and Satti are affiliated with the Temple University Lung Center, Temple University Health System, Ambulatory Care Center, Philadelphia, Pennsylvania. Ms Cuesta is affiliated with the Department of Epidemiology and Biostatistics, College of Health Sciences, Temple University, Philadelphia, Pennsylvania. Dr Morrison is affiliated with the Department of Psychiatry and Behavioral Sciences, Temple University School of Medicine Episcopal Campus, Philadelphia, Pennsylvania. Dr Leone is affiliated with the Pulmonary, Allergy, and ditions of chronic bronchitis and emphysema. ${ }^{1}$ As the third leading cause of morbidity and mortality in American adults, ${ }^{2}$ COPD disproportionally affects African-Ameri-

\footnotetext{
Critical Care Division, University of Pennsylvania Presbyterian Medical Center, Philadelphia, Pennsylvania.

Dr Patterson presented a version of this paper at the American Thoracic Society annual meeting, held May 15-20, 2015, in Denver, Colorado.

This work was supported by the College of Public Health at Temple University as part of the Dean's Incentive Award to Freda Patterson and Aditi Satti. This work was also supported by an Institutional Development Award (IDeA) Center of Biomedical Research Excellence from the National Institute of General Medical Sciences of the National Institutes of Health under grant number P20GM113125 (to Freda Patterson). The authors have disclosed no conflicts of interest.
} 
can groups. For example, African-Americans tend to develop COPD at an earlier age and with less intense smoking habits than whites. ${ }^{3}$ Among COPD patients under the age of $55 \mathrm{y}$ who smoke, $42 \%$ are African-American, whereas only $14 \%$ are white. ${ }^{4}$ As a COPD-related condition, asthma is disproportionately experienced in the African-American population. African-Americans are twice as likely to report a history of asthma (33\% vs $15 \%)$, and have more frequent and severe respiratory exacerbations, despite similar lung function and fewer pack-years of smoking than whites. ${ }^{5}$ Moreover, African-Americans are more likely to have a dual diagnosis of COPD and asthma (37\% vs $20 \%$ in whites), experience more frequent and severe exacerbations and greater radiographic evidence of gas trapping. ${ }^{5}$ Compared with whites, African-Americans experience more severe COPD symptoms and greater declines in quality of life following exacerbation of COPD symptoms. ${ }^{6-8}$ Addressing COPD and poor pulmonary health in African-Americans is clearly a clinical and public health priority.

First-line prevention and treatment approaches for COPD include smoking cessation as well as reducing physical inactivity and sedentary behaviors. ${ }^{9,10}$ Whereas current smoking rates for white and African-American groups are comparable (18.2\% vs $17.5 \%),{ }^{11}$ smoking behaviors differ between these groups: African-Americans smoke fewer cigarettes per day, ${ }^{12,13}$ have a higher level of nicotine dependence, ${ }^{14}$ are more likely to smoke higher nicotine/tar cigarettes, inhale more deeply, and puff more frequently, ${ }^{15,16}$ resulting in greater exposure to tobacco smoke toxins and greater susceptibility to disease and illness. ${ }^{16}$ African-Americans also have a reduced ability to metabolize nicotine, thus prolonging nicotine exposure and dependence levels. ${ }^{16-19}$ In terms of smoking cessation behaviors, African-American smokers are more likely to use self-help interventions when quitting ${ }^{12}$ but are less likely to successfully quit than whites. ${ }^{20}$ Thus, African-Americans bear a disproportionate burden of the negative health effects of tobacco use and are a treatment-resistant group for smoking cessation as compared with whites.

A plethora of evidence documents that at the group level, increasing severity of COPD is associated with declines in physical function and capacity, ${ }^{21}$ whereas physical inactivity is a strong predictor of poorer COPD health outcomes, hospitalization, and mortality. ${ }^{22,23}$ On this basis,

Correspondence: Freda Patterson PhD MSc, Center of Biomedical Research Excellence (COBRE) in Cardiovascular Health and Department of Behavioral Health and Nutrition, College of Health Sciences, University of Delaware, 026 North College Avenue, Carpenter Sports Building, Newark, DE 19711. E-mail: fredap@udel.edu.

DOI: $10.4187 /$ respcare 04958

\section{QUICK LOOK}

\section{Current knowledge}

Smoking cessation and increased physical activity are front-line treatments for cardiopulmonary disease, but many underserved (eg, urban, African-American) smokers in pulmonary care continue to smoke and are largely inactive.

\section{What this paper contributes to our knowledge}

Attendance to smoking cessation programs among underserved, African-American pulmonary care subjects was poor, particularly among those who did not yet have a diagnosis of COPD and who did not have a familial history of cancer (maternal cancer, in particular). Qualitatively, pulmonary care subjects reported wanting to quit smoking and be more physically active, but cited barriers included: strong beliefs about the inability to engage in these behaviors, a belief that quitting and increased activity might exacerbate poor health, and an inability to obtain pharmacotherapy.

the Global Initiative for Chronic Obstructive Lung Disease (GOLD) recommends that all patients with COPD engage in daily physical activity. ${ }^{24}$ Yet, African-Americans are less likely to achieve regular physical activity and are more sedentary. ${ }^{25,26}$ Importantly, guidelines for the translation of the GOLD recommendations at the clinical and community level have yet to be defined. More immediately, the acceptability of and willingness to engage in physical activity by COPD patients who smoke also remains an open question. Given the tremendous benefits of increased physical activity tolerance on the amelioration of COPD symptoms, ${ }^{27}$ reduced exacerbations and hospitalizations, ${ }^{28,29}$ and improved quality of life, ${ }^{30,31}$ evaluating the potential for African-American smokers (who tend to be diagnosed younger and experience disproportionately more severe COPD symptoms than whites) to engage in physical activity could be transformational to COPD treatment in this population.

Sustained smoking cessation is directly proportional to program attendance, ${ }^{32}$ yet few studies have examined this dimension of cessation outcome in African-Americans. Trials evaluating the efficacy of pharmacotherapies for nicotine dependence typically include a small proportion of African-Americans $(\sim 10 \%),{ }^{33,34}$ whereas trials that have exclusively recruited African-American smokers have had a wide range of adherence rates, from as low as $20 \%^{35,36}$ up to $74 \%$ in some pilot studies $(N \leq$ 50). ${ }^{37,38}$ Few studies have examined the predictors of smoking cessation program adherence exclusively in African-American populations. ${ }^{39,40}$ In one study, a higher 


\section{Smoking Cessation in Pulmonary Care Subjects}

smoking rate predicted dropout in a sample of pregnant African-American women, ${ }^{39}$ whereas another community-based program showed that being a high school graduate predicted adherence. ${ }^{40}$ The barriers and predictors to smoking cessation program attendance among African-American smokers with poor pulmonary health remain an open question. ${ }^{4}$

To begin to address this gap, the current study used extracted medical chart data to examine demographic, smoking behavior, and health status differences in smokers who enrolled (vs those not enrolled) and those who attended (vs those who did not attend) a 3-session smoking cessation program offered by an urban center hospitalbased pulmonary clinic $(N=253)$. Qualitatively, preferences and barriers to smoking cessation and physical activity in a sample of high-risk African-Americans with poor pulmonary health who smoked were explored through focus groups $(n=41)$.

\section{Methods}

\section{Study Overview}

The current study used a mixed methods design utilizing quantitative and qualitative tools to assess predictors of smoking cessation program enrollment. Quantitative analysis examined the demographic, health status, and smoking behavior predictors of underserved smokers ( $\sim 70 \%$ are African-American) with COPD who enrolled (vs those who did not enroll) and attended (vs those who did not attend) the hospital-based smoking cessation clinic between June 1, 2013 and May 31, 2014. A qualitative assessment of the barriers, intentions, and expectations for smoking cessation and physical activity was also conducted with enrollers and non-enrollers to the hospital-based smoking cessation clinic. All study procedures were institutional review board-approved.

The hospital-based smoking cessation program is an evidence-based, 3-session program, to which all pulmonary patients who smoke are referred. ${ }^{41}$ The program consists of an initial comprehensive health assessment with a pulmonologist to discuss level of nicotine dependence, medical history, and pharmacotherapy preference for smoking cessation. Following this baseline visit, all clinic patients are offered 3 group counseling sessions with a certified tobacco treatment specialist and a follow-up appointment for relapse prevention. The first of the 3 appointments typically occurs within 4-6 weeks of the baseline visit, and participants are encouraged to set a target quit date for the morning of their second visit. The group counseling sessions cover topics including smoking as an addictive behavior, triggers for smoking, effective treatments for smoking cessation, developing coping strategies for triggers to smoke, and relapse prevention. Social sup- port is encouraged in the group setting, and participants are encouraged to share challenges and problem-solve with the group. All participants are prescribed their selected form of pharmacotherapy.

\section{Study Procedures}

Quantitative Study. A medical chart extraction for all subjects, smokers age $\geq 18$ y who were referred to a hospital-based smoking cessation clinic between June 1, 2013 and May 31, 2014, was completed $(N=253)$. These data were used to examine demographic, health status, and smoking behavior characteristics of smoking cessation program enrollers (vs non-enrollers) and attendees (vs nonattendees). No individuals were excluded based on race, ethnicity, sex, or HIV status.

Qualitative Study. Five focus group sessions were held in a sample of adult pulmonary clinic patients, who attended the clinic between June 1, 2013 and May 31, 2014 (the same sample used in the chart extraction study). Twelve participants were enrolled in each focus group. A mix of smoking cessation program non-enrollers and enrollers were scheduled for each focus group to achieve a balanced group of subjects who had demonstrated willingness and unwillingness to participate in the clinic smoking cessation program.

A focus group protocol with standardized questions and follow-up probing questions was used to guide the focus group conversation. A trained focus group facilitator led the groups. Focus group questions centered on the following topics: (1) feelings, knowledge, attitudes, and beliefs about smoking and physical activity and their effects on COPD; (2) desire to quit smoking and increase levels of physical activity; (3) identification of barriers and incentives to quit smoking and increase levels of activity; (4) willingness to use technology and pharmacotherapy to facilitate behavior change; and (5) feelings about using small increases in physical activity to help reduce or eliminate tobacco use. Participants were provided with a $\$ 50$ stipend for their group attendance.

\section{Study Measures for the Quantitative Study}

The main outcome variables of interest are program enrollment and attendance. Program enrollment was defined as attending the first counseling session (yes/no), whereas program attendance was defined as attending the third and final program session (yes/no). Study variables extracted for each subject in the retrospective chart review included the demographic variables of age, sex (male vs female), and race (white, African-American, Asian, Hispanic, and other). Pretreatment tobacco use variables captured included number of cigarettes per 
day $(<10,11-20,21-30$, and $>30)$, nicotine dependence, and number of quit attempts. Nicotine dependence was measured using the 6-item Fagerström Test for Nicotine Dependence. ${ }^{42}$ For the current analysis, the total Fagerström test score was dichotomized so that a score of $\geq 5$ indicated moderate to high levels of dependence. The number of quit attempts and use of FDAcleared smoking cessation medications in the last year (yes/no) were also assessed.

Cardiopulmonary-related variables included COPD diagnosis (yes/no) and COPD exacerbations in the last year (yes/no). A COPD diagnosis was given when post-bronchodilator $\mathrm{FEV}_{1} / \mathrm{FVC}$ was $<0.70^{43}$; in cases where subjects exhibited advanced COPD symptoms (eg, frequent respiratory infections, sputum production dyspnea, and chronic cough) but $\mathrm{FEV}_{1} / \mathrm{FVC}$ was $\geq 0.70$, clinical judgment was used to make the COPD diagnosis. ${ }^{44-46}$ Support for this diagnostic approach can be garnered from data showing the vulnerability to COPD exacerbations experienced by habitual smokers even in the presence of $\mathrm{FEV}_{1} / \mathrm{FVC} \geq 0.70 .{ }^{45}$ Standard measures of pulmonary mechanics obtained through baseline spirometry were collected and included percent-of-predicted FVC, percent-ofpredicted $\mathrm{FEV}_{1}$, percent-of-predicted $\mathrm{FEV}_{1} / \mathrm{FVC}$, 47 and total lung capacity $(\%)$. These measures are standard indicators of pulmonary function. A battery of health status variables were also extracted, including body mass index $\left(\mathrm{kg} / \mathrm{m}^{2}\right)$ and a current diagnosis of coronary artery disease, hypertension, diabetes, HIV, hepatitis C, chronic heart failure, depression, and anxiety. Personal, maternal, and paternal history of any type of cancer was recorded dichotomously (yes/no).

\section{Analytic Approach}

Quantitative Study. Descriptive statistics were generated for all study variables. For continuous variables, mean and SD values were calculated, whereas for categorical variables, the number and percentage for each group were reported. Bivariate association of all demographic, health status, behavior, and tobacco use variables with the outcomes of program enrollment and program attendance were estimated using $t$ tests for continuous variables and chisquare tests for categorical variables. Last, a separate logistic regression model of program enrollment and program attendance was generated. Variables associated with these outcomes at $P<.30$ in the bivariate analysis were included in the initial model.

Qualitative Study. To analyze the focus group data, each focus group was recorded and subsequently transcribed. Transcripts were analyzed using the key stages of familiarization, identifying a thematic framework indexing, charting, mapping, and interpretation. ${ }^{48}$ Thematic catego- ries were identified, and relevant quotes were indexed and charted according to those categories to reduce data. ${ }^{49}$ Data were coded by 3 of the investigators (FP, DSZ, and AS). Interpretation and verification of supporting quotes was conducted insofar as assessing context and identifying emergent themes as well as the frequency, specificity, intensity, and categorization of comments and "big ideas." Coders met regularly to compare coding categories and allocation of comments to specific categories. Instances of incongruent coding were reviewed and reconciled with utmost adherence to the coding scheme.

Main ideas for each of the following content areas were extracted: (1) feelings, knowledge, attitudes, and beliefs about smoking and physical activity and their effects on COPD; (2) desire to quit smoking and increase levels of physical activity; (3) identification of barriers and incentives to quit smoking and increase levels of activity; (4) willingness to use technology and pharmacotherapy to facilitate behavior change; and (5) feelings about using small increases in physical activity to help reduce or eliminate tobacco use.

\section{Results}

\section{Study 1: Quantitative Examination of Predictors of Smoking Cessation Program Enrollment and Attendance}

Participant Characteristics. Two hundred fifty-three pulmonary clinic subjects were referred to the hospitalbased smoking cessation program between June 1, 2013 and May 31, 2014 and are included in the current analysis. Of these, 174 (69\%) were African-American, 26 (10\%) were white, and 53 (21\%) self-identified as other race. Mean age was $56 \pm 9.63$ y. Forty-three percent of the sample reported smoking 10 or more cigarettes per day, and $61 \%$ reported making a quit attempt in the last year. Almost half of the sample had COPD (49\%). Of the 253 pulmonary clinic subjects, $59 \%(n=150)$ enrolled in the hospital-based smoking cessation program (ie, attended session 1), and 40 attended the program in full (27\% of baseline attendees; $16 \%$ of the total sample).

Variables Associated With Smoking Cessation Program Enrollment and Attendance. Although there were no demographic differences in program enrollment, smokers who reported smoking more cigarettes per day $(P=.009)$, made a quit attempt in the last year $(P<.001)$, had a COPD diagnosis $(P=.02)$, and did not have a hepatitis $\mathrm{C}$ diagnosis $(P=.02)$ were significantly more likely to enroll in the 3 -session smoking cessation program (Table 1).

In terms of program attendance, participants who were older $(P=.054)$, smoked fewer cigarettes at baseline 
Table 1. Variables Associated With Program Enrollment

\begin{tabular}{|c|c|c|c|}
\hline \multirow{2}{*}{ Variables } & \multicolumn{2}{|c|}{ Program Enrollment } & \multirow{2}{*}{$P$} \\
\hline & Yes $(n=150 ; 59 \%)$ & No $(n=103 ; 41 \%)$ & \\
\hline \multicolumn{4}{|l|}{ Demographic/tobacco use } \\
\hline Sex, $n(\%)$ & & & .34 \\
\hline Male & $101(67.3)$ & $66(64.1)$ & \\
\hline Female & $49(32.7)$ & $37(35.9)$ & \\
\hline Race, $n(\%)$ & & & .17 \\
\hline African-American & $110(73.3)$ & $64(62.1)$ & \\
\hline Caucasian & $13(8.7)$ & $13(12.6)$ & \\
\hline Other & $27(18)$ & $26(25.2)$ & \\
\hline Age, mean \pm SD y & $56.63 \pm 10.11$ & $54.99 \pm 9.25$ & .19 \\
\hline Cigarettes/day, $n(\%)$ & & & .009 \\
\hline$\leq 10$ & $51(34)$ & $57(55.3)$ & \\
\hline $11-20$ & $57(38)$ & $28(27.2)$ & \\
\hline $21-30$ & $25(16.7)$ & $10(9.7)$ & \\
\hline$\geq 31$ & $17(11.3)$ & $8(7.8)$ & \\
\hline Nicotine dependence, $n(\%)$ & & & .31 \\
\hline Low (Fagerström test score $0-4$ ) & $48(33.3)$ & $0(0)$ & \\
\hline Moderate to high (Fagerström test score 5-10) & $96(66.7)$ & $1(100)$ & \\
\hline Smoking cessation attempt in the last year, $n(\%)$ & & & $<.001$ \\
\hline Yes & $106(70.7)$ & $49(47.6)$ & \\
\hline No & $44(29.3)$ & $54(52.4)$ & \\
\hline \multicolumn{4}{|l|}{ Pretreatment cardiopulmonary } \\
\hline COPD diagnosis, $n(\%)$ & $42(40.8)$ & $83(55.3)$ & .02 \\
\hline COPD exacerbations, $n(\%)$ & $9(6 \%)$ & $12(11.7 \%)$ & .87 \\
\hline $\mathrm{FEV}_{1}$, mean $\pm \mathrm{SD} \%$ predicted & $67.86 \pm 13.28$ & $65.03 \pm 15.96$ & .75 \\
\hline $\mathrm{FEV}_{1} / \mathrm{FVC}$, mean $\pm \mathrm{SD} \%$ predicted & $67.86 \pm 13.28$ & $65.03 \pm 15.96$ & .22 \\
\hline Total lung capacity, mean \pm SD $\%$ predicted & $86.35 \pm 14.93$ & $89.65 \pm 15.34$ & .21 \\
\hline \multicolumn{4}{|l|}{ Pretreatment health status } \\
\hline Body mass index, mean $\pm \mathrm{SD} \% \mathrm{~kg} / \mathrm{m}^{2}$ & $31.34 \pm 8.56$ & $31.33 \pm 8.42$ & .99 \\
\hline Coronary artery disease & $32(21.3)$ & $14(13.5)$ & .08 \\
\hline History of cancer & $23(15.3)$ & $9(8.7)$ & .09 \\
\hline Hypertension & $98(65.3)$ & $60(58.3)$ & .16 \\
\hline Diabetes & $55(36.7)$ & $31(30.1)$ & .17 \\
\hline HIV & $4(2.7)$ & $8(7.8)$ & .059 \\
\hline Hepatitis C & $6(4.0)$ & $12(11.7)$ & .02 \\
\hline Chronic heart failure & $15(10)$ & $10(9.7)$ & .56 \\
\hline Asthma & $41(27.3)$ & $23(22.3)$ & .23 \\
\hline Depression & $75(50)$ & $42(40.8)$ & .09 \\
\hline Anxiety & $23(22.3)$ & $43(28.7)$ & .16 \\
\hline Mother had cancer & $30(20)$ & $12(11.7)$ & .055 \\
\hline Father had cancer & $23(15.3)$ & $17(16.5)$ & .47 \\
\hline
\end{tabular}

$(P=.02)$, reported not trying to quit in the last year at baseline $(P=.036)$, had a history of cancer $(P=.02)$, and had a diagnosis of COPD $(P<.001)$, were significantly more likely to attend the 3 -session smoking cessation program (Table 2).

Predictors of Smoking Cessation Program Enrollment and Attendance. In a logistic regression model of program enrollment, participants who smoked more cigarettes per day (odds ratio $[\mathrm{OR}]=1.73, P<.001$ ), reported making a cessation attempt in the last year
$(\mathrm{OR}=3.03, P<.001)$, had coronary artery disease $(\mathrm{OR}=2.20, P=.048)$, had a COPD diagnosis $(\mathrm{OR}=2.46$, $P=.004)$, and had more COPD exacerbations $(\mathrm{OR}=1.32$, $P=.036)$ had a higher likelihood of program enrollment (Table 3).

In terms of program attendance, participants with a COPD diagnosis (OR $=4.65, P=.030)$, a mother who had ever had a cancer diagnosis $(\mathrm{OR}=4.49$, $P=.03)$, and a lower $\mathrm{FEV}_{1} / \mathrm{FVC}(\mathrm{OR}=1.11, P=$ .007) had a higher likelihood of attending the program (Table 4). 
Table 2. Variables Associated With Program Attendance

\begin{tabular}{|c|c|c|c|}
\hline \multirow{2}{*}{ Variables } & \multicolumn{2}{|c|}{ Program Attendance } & \multirow{2}{*}{$P$} \\
\hline & Yes $(n=40 ; 16 \%)$ & No $(n=213 ; 84 \%)$ & \\
\hline \multicolumn{4}{|l|}{ Demographic/tobacco use } \\
\hline Sex, $n(\%)$ & & & .08 \\
\hline Male & $22(55)$ & $145(68.1)$ & \\
\hline Female & $18(45)$ & $68(31.9)$ & \\
\hline Race, $n(\%)$ & & & .24 \\
\hline African-American & $32(80)$ & $142(66.7)$ & \\
\hline Caucasian & $3(7.5)$ & $23(10.8)$ & \\
\hline Other & $5(12.5)$ & $48(22.5)$ & \\
\hline Age, mean \pm SD y & $58.65 \pm 8.07$ & $55.46 \pm 9.83$ & .054 \\
\hline Cigarettes/day & & & .02 \\
\hline$\leq 10$ & $10(25)$ & $98(46)$ & \\
\hline $11-20$ & $15(37.5)$ & $70(32.9)$ & \\
\hline $21-30$ & $11(27.5)$ & $24(11.3)$ & \\
\hline$\geq 31$ & $4(10)$ & $21(9.8)$ & \\
\hline Nicotine dependence & & & .43 \\
\hline Low (Fagerström test score $0-4$ ) & $11(27.5)$ & $37(35.2)$ & \\
\hline Moderate to high (Fagerström test score $5-10$ ) & $29(72.5)$ & $68(64.8)$ & \\
\hline Smoking cessation attempt in the last year & & & .036 \\
\hline Yes & $30(75)$ & $125(58.7)$ & \\
\hline No & $10(25)$ & $88(41.3)$ & \\
\hline \multicolumn{4}{|l|}{ Pretreatment cardiopulmonary } \\
\hline COPD diagnosis & $31(77.5)$ & $94(44.1)$ & $<.001$ \\
\hline COPD exacerbations & $3(7.5)$ & $18(8.5)$ & .57 \\
\hline $\mathrm{FEV}_{1}$, mean $\pm \mathrm{SD} \%$ predicted & $72.71 \pm 17.86$ & $72.76 \pm 20.72$ & .10 \\
\hline $\mathrm{FEV}_{1} / \mathrm{FVC}$, mean $\pm \mathrm{SD} \%$ predicted & $70.39 \pm 10.56$ & $65.88 \pm 15.06$ & .09 \\
\hline Total lung capacity, mean $\pm \mathrm{SD} \%$ predicted & $83.76 \pm 14.95$ & $88.62 \pm 15.03$ & .10 \\
\hline \multicolumn{4}{|l|}{ Pretreatment health status } \\
\hline Body mass index, $\mathrm{kg} / \mathrm{m}^{2}$ & $30.87 \pm 7.22$ & $31.42 \pm 8.68$ & .71 \\
\hline Coronary artery disease, $n(\%)$ & $10(25)$ & $36(16.9)$ & .16 \\
\hline History of cancer, $n(\%)$ & $10(25)$ & $22(10.3)$ & .02 \\
\hline Hypertension, $n(\%)$ & $31(77.5)$ & $127(59.6)$ & .02 \\
\hline Diabetes, $n(\%)$ & $16(40)$ & $70(32.9)$ & .24 \\
\hline $\mathrm{HIV}, n(\%)$ & $1(2.5)$ & $11(5.2)$ & .41 \\
\hline Hepatitis C, $n(\%)$ & $5(12.5)$ & $13(6.1)$ & .13 \\
\hline Chronic heart failure, $n(\%)$ & $6(15)$ & $19(8.9)$ & .18 \\
\hline Asthma, $n(\%)$ & $11(27.5)$ & $53(24.9)$ & .43 \\
\hline Depression, $n(\%)$ & $20(50)$ & $97(45.5)$ & .36 \\
\hline Anxiety, $n(\%)$ & $10(25)$ & $56(26.3)$ & .52 \\
\hline Mother had cancer, $n(\%)$ & $10(25)$ & $32(15)$ & .10 \\
\hline Father had cancer, $n(\%)$ & $8(20)$ & $32(15)$ & .28 \\
\hline
\end{tabular}

\section{Study 2: Qualitative Examination of Barriers and Facilitators for Smoking Cessation and Physical Activity}

Focus Group Participants. Of the 63 participants scheduled to attend one of the 5 focus groups, 41 participated (65\% show rate). Focus group participants were $61 \%$ female, $79 \%$ African-American, and $7.3 \%$ white; the mean age was $53.6 \pm 7.4 \mathrm{y}$, and $24(59 \%)$ had previously enrolled in the hospital-based smoking cessation program. Five participants attended focus group 1, 13 were in group 2, 4 in group 3, 12 in group 4, and 7 in group 5.

\section{Focus Group Emergent Results}

Feelings, Knowledge, Attitudes and Beliefs About Smoking and Physical Activity and Their Effects on COPD. Some of the main themes emerging from this line of questioning included reasons for smoking, strong belief about the negative effects of smoking on COPD, and a belief that physical activity or exercise would exacerbate COPD symptoms. In terms of the reasons for smoking, participants pervasively spoke of the strong addictive component to cigarettes and the magnitude of triggers to smoke (eg, being around other smokers, strong emotions) that 
Table 3. Predictors of Program Enrollment

\begin{tabular}{lccc}
\hline \hline \multicolumn{1}{c}{ Variable } & $\begin{array}{l}\text { Odds } \\
\text { Ratio }\end{array}$ & $95 \%$ CI & $P$ \\
\hline Sex (female $=1$ ) & 1.439 & $0.773-2.676$ & .25 \\
Baseline nicotine dependence & 1.731 & $1.279-2.345$ & $<.001$ \\
Cessation attempt in last year & 3.034 & $1.698-5.421$ & $<.001$ \\
Coronary artery disease & 2.198 & $1.005-4.806$ & .048 \\
History of cancer & 2.181 & $0.865-5.496$ & .10 \\
COPD & 2.462 & $1.336-4.538$ & .004 \\
COPD exacerbations & 1.324 & $0.113-0.928$ & .036 \\
Asthma & 1.481 & $0.758-2.891$ & .25 \\
Depression & 1.652 & $0.925-2.949$ & .09 \\
Mother had cancer & 2.040 & $0.932-4.464$ & .07 \\
\hline
\end{tabular}

Table 4. Predictors of Program Attendance

\begin{tabular}{lcll}
\hline \hline \multicolumn{1}{c}{ Variable } & Odds Ratio & \multicolumn{1}{c}{$95 \%$ CI } & $P$ \\
\hline Sex $($ female $=1)$ & 0.438 & $0.157-1.225$ & .12 \\
Coronary artery disease & 0.441 & $0.138-1.414$ & .17 \\
COPD & 4.647 & $1.163-18.576$ & .030 \\
Hepatitis C & 5.771 & $0.449-74.128$ & .18 \\
Mother had cancer & 4.492 & $1.184-17.037$ & .03 \\
FEV $_{1} /$ FVC & 1.110 & $1.029-1.197$ & .007 \\
\hline
\end{tabular}

forced them to maintain their smoking habit. Combined, these reasons for smoking conveyed a strong feeling of helplessness and lack of control over the smoking habit.

Focus group participants did endorse the belief that smoking had a strong negative health effect on their breathing and pulmonary health. This belief was nearly always followed up with a comment about the strength of nicotine addiction and the inability to quit. In terms of physical activity, 3 themes of interest emerged. First, participants had differing ideas of what it meant to be physically active. Whereas several spoke of playing with their grandchildren as their primary mode of physical activity, others spoke of doing tai chi or riding an exercise bicycle for exercise: thus, there was considerable range in the interpretation of what being physically active meant. A second theme was a sense that being active was not possible because of COPD. For example, when participants were asked about how they felt physical activity would affect their breathing and pulmonary health, the general consensus from the groups was that, by in large, they were unable to exercise because of their poor pulmonary health. Related to this second theme was the third idea, which was a fear of being active in case the additional stress would initiate a flare up or other negative health event. There was almost a sense of melancholy in the discussion about physical activity and COPD, whereby several participants expressed a desire to do more but a fear that doing more would actually have negative health effects (see Table 5).
Desire to Quit Smoking and Increase Levels of Physical Activity; Barriers and Incentives to Quit Smoking and Increase Levels of Activity. Across all groups there was a general consensus among participants that they would like to successfully quit smoking and be more active. In terms of the barriers and facilitators to achieving these goals, we identified the following themes: (1) intense shame and guilt that came from being a smoker; (2) fear of discomfort or getting sicker after cessation or becoming more active; (3) physical activity and/or exercise being boring and not fun; (4) lack of access to support for smoking cessation and physical activity; (5) need for social support to quit and be more active.

The intense shame and guilt felt by focus group participants because of their smoking was one of the most compelling sentiments that emerged from the groups. Participants talked extensively about letting their family members down by continuing to smoke and the intense guilt that they carried because of their inability to quit. Also reported was a fear of quitting and how quitting might actually serve to worsen health. This belief that quitting smoking could degrade health was supported by anecdotal accounts of neighbors or friends whose cancer or heart attack came soon after smoking cessation. On balance though, the group consensus was that quitting smoking was still preferable (see Table 6).

When asked about being more physically active, participants voiced a mix of desire to increase activity combined with a fear that increasing activity could worsen health. In addition to fears about increased physical activity worsening health, participants also noted that exercise could be boring and not fun. Participants noted that social support was vital to regular participation in physical activity. Importantly, the group noted that support that was encouraging and positive was preferable to yelling and reminders about what they were failing to achieve. The idea of having neighbors to walk with, do exercises in the home with, and quit smoking with was positively endorsed by the group.

Willingness to Use Technology and Pharmacotherapy to Quit Smoking and/or Increase Physical Activity Levels. When asked about their willingness to use technology, such as smart phone apps and text messaging, to support smoking reduction or cessation and physical activity, the response was mixed. Whereas some participants felt that such communication might be helpful and supportive, others cited concerns about an invasion into their time and space. Participants noted how easy it was for them to ignore text, e-mail, and other social media-type messages that came too frequently or otherwise seemed invasive.

By contrast, participants overwhelmingly endorsed the use of pharmacotherapy to support smoking cessation. Many participants became vocally agitated when describing the challenges that they had faced in the past when 


\section{Smoking Cessation in Pulmonary Care Subjects}

Table 5. Emergent Themes and Quotes Related to the Questions About Feelings, Knowledge, Attitudes, and Beliefs About Smoking and Physical Activity and Their Effects on COPD

\begin{tabular}{|c|c|}
\hline Emergent Theme & Related Quote \\
\hline \multicolumn{2}{|l|}{ Reasons for smoking } \\
\hline Powerful addiction & $\begin{array}{l}\text { And I realized it's not just, it's a spiritual thing, it's a physical thing cause there's a hundred and thirty } \\
\text { chemicals in a cigarette, one cigarette, that's powerful...Cause that's all, and your body's craving all } \\
\text { that. } \\
\text { It's an addiction. } \\
\text { It's [because of] the chemicals I smoke...cigarettes come to be friends to you. } \\
\text { I guess we have like the nicotine in our system like that and I guess it craving for that cigarette... } \\
\text { I've done every drug known to man on this planet...except for heroin...And I've quit everything; I said "I } \\
\text { don't want to do it no more" bam that's it...Cigarettes, I can't shake it...is something that they have in } \\
\text { these cigarettes... } \\
\text { [I may not have smoked that day]...but then if I go to the store for something, anything it doesn't have } \\
\text { to be cigarettes, it's just habit forming, you know, I'll get a pack. }\end{array}$ \\
\hline Magnitude of triggers & $\begin{array}{l}\text { Too many triggers. If I could deal with those triggers and find ways to cope with that, I think I could } \\
\text { beat cigarettes. } \\
\text {...It's one of the reasons why I smoke a lot too because I get stressed out. } \\
\text { I smoke sometimes when I'm bored too. } \\
\text { It relaxes me. } \\
\text { And then after meal I need a cigarette. } \\
\text { But its triggers are a big, big part more than stress I think. } \\
\text { But then I, you know something happens or you get bad news and you know here you go lightin' up... } \\
\text { It seems like my brain says now you're outside now you can smoke. } \\
\text { I quit smoking } 2 \text { weeks ago this day on Wednesday, I was just so fed up I said what's the real problem } \\
\text { here, is it the cigarettes or is it my way of thinking about cigarettes. So I didn't smoke I, I had one } \\
\text { in the morning....and then I went the whole day without smoking. But the whole day I realized I gotta } \\
\text { stay in the house, I go outside I'm gonna buy a pack of cigarettes. So I stayed in the house...it was } \\
\text { the only way [not to smoke]. }\end{array}$ \\
\hline Negative effects of smoking & $\begin{array}{l}\text { Stops me from doing things, it's like sometimes I wanna play with my grandkids and I get out of } \\
\text { breath too fast. } \\
\text { A lot of things I can't do cause I'll be out of breath most of the time. And I know it comes from the } \\
\text { cigarettes. } \\
\text {...Takes your energy. } \\
\text { Everything, it affects everything. } \\
\text { It makes you look old. } \\
\text { [I] used to cut my own grass and all that. Last year I had to hire somebody to do it, cause every time I } \\
\text { would get started within } 5 \text { or } 6 \text { min I'd be out of breath. } \\
\text { Well my physical activity is almost nil to none, because I used to do everything, I used to be in shape, } \\
\text { I used to, fairly muscular, I was real strong, and all that's gone away. Used to cut my own grass and } \\
\text { all that. Last year I had to hire somebody to do it, cause every time I would get started within } 5 \text { or } 6 \\
\text { min I'd be out of breath. Then I would foolishly go in the house light up a cigarette...smoking is what } \\
\text { did this to me in the first place. } \\
\text { I got COPD from smoking. }\end{array}$ \\
\hline $\begin{array}{l}\text { Types of physical activity in which } \\
\text { participants engage }\end{array}$ & $\begin{array}{l}\text { I paint, I play with my grandkids. } \\
\text { I pick up my niece every day from day care. That's the extra physical activity that I do. So, basically I } \\
\text { can do ok. } \\
\text { Up and down steps, sweeping mopping cooking, washing clothes, it's all physical activity to me. } \\
\text { I swim. I fish. I hunt. } \\
\text { I walk a lot. } \\
\text { I dance a lot. } \\
\text { I like to play with my kids, you know so yeah; so I'm running around with them, know wrestle with } \\
\text { them, you know do activities with them cause that's basically what keeps me healthy and keeps me } \\
\text { young. } \\
\text { [I have an] exercise bike in the house that I ride } 2,3 \text { times a week when I can. } \\
\text { I do Tai Chi twice a week. }\end{array}$ \\
\hline
\end{tabular}




\section{Smoking Cessation in Pulmonary Care Subjects}

Table 5. Continued

\begin{tabular}{l}
\hline \hline \multicolumn{1}{c}{ Emergent Theme } \\
$\begin{array}{l}\text { Physical activity or exercise is too } \\
\text { difficult and/or would exacerbate } \\
\text { COPD symptoms }\end{array}$ \\
We can't [exercise] because we got too short of breathing. \\
I wish to do some exercise. I'm trying here in the house, I'm trying next to the house, but you know \\
we can't because we got too short of breathing. \\
[translating for grandmother] She knows what she has to do increased physical activity...But it's that she \\
uh physically can't because of a lot of the health issues... \\
I was saying, it all depends on what's ailing you. You, you, you got emphysema and things of that \\
nature, it don't matter how much you exercise, whatever. You only going to be allowed to do so \\
much. \\
I can't walk up those steps. I don't walk up the steps, one flight that's about it...I get too frightened and \\
rest, and then walk the rest of them. \\
I used to walk but don't do that anymore since I started smoking. \\
I want to exercise! You know because I have put on weight...But I can't...'m not going to say I can't, I \\
uh I just I don't exercise because I don't have the air... \\
We can't [exercise] because we got too short of breathing. \\
Because the best I ever felt, even with COPD, was when I was going to the gym at least 3 to 4 times a \\
week and getting my cardio up and I was eating better, smoking less I felt, you know, I was getting \\
my strength back...I don't think I could do that now... \\
I can't walk from here to like, you know...say too long...down the hall without being out of breath. \\
I mean I would love to run, uh, a whole mile I, I wouldn't even make it to the corner, I'll pass out.
\end{tabular}

trying to get pharmacotherapy, specifically varenicline. To the extent that varenicline was widely endorsed by focus group participants as being an effective treatment for smoking cessation, it was equally noted as being difficult to acquire, both in terms of health-care practitioners being hesitant to prescribe it and insurance not providing coverage. There was almost a sense of wistfulness, in that if varenicline could be acquired, smoking cessation would, in fact, be possible (see Table 7).

Feelings About Using Small Increases in Physical Activity to Help Reduce or Eliminate Tobacco Use. The line of questioning about using physical activity to help reduce or eliminate tobacco use was met with limited response. Participants generally reiterated the benefits of more physical activity (as discussed above) but also noted the practical difficulty of doing so, due to vulnerability to pulmonary flare-ups and difficulty breathing, both of which made it difficult to engage in physical activity. The concept of leveraging one behavior (smoking cessation) through the other (increased activity) was thus not conceivable to this group. Questions about using physical activity as a tool to reduce or eliminate tobacco use were sometimes met with silence and short sentence answers following a prompt from the group facilitator.

\section{Discussion}

Tobacco use is a chronic, relapsing condition that requires a treatment maintenance approach so that abstinence can be sustained..$^{50}$ The current study used a mixed methods approach to identify determinants of smoking ces- sation program enrollment and attendance as well as feelings and beliefs about smoking cessation and increased levels of physical activity in a sample of mostly AfricanAmerican smokers. The main findings of this study were that in this high-risk population, smokers who had a COPD diagnosis and who had a mother with a history of cancer were at least twice as likely to attend the 3-session smoking cessation program. Qualitatively, African-American smokers cited a strong desire to quit and increase levels of physical activity but also believed that these behavior changes could incite poorer health. Participants widely endorsed a need for greater support, including access to pharmacotherapy, to help with cessation efforts. Combined, these results add to our understanding about subgroups of smokers with pulmonary disease who are at greater risk for continued smoking as well as knowledge and treatment access gaps that may be hindering treatment initiation and maintenance.

Our finding that having a COPD diagnosis was predictive of smoking cessation program attendance converges with cognitively based models of health behavior change (eg, the health belief model) that assert increased disease severity is a determinant of behavior change. ${ }^{51}$ From an empirical perspective, however, the effects of disease status on smoking cessation are less clear. Prevalence data suggest that between 54 and $77 \%$ of patients with mild COPD and between 38 and $51 \%$ of patients with severe COPD are current smokers, ${ }^{52,53}$ whereas other data have shown that only $30 \%$ of smokers with COPD seek smoking cessation treatment. ${ }^{54}$ Given that smoking cessation among pulmonary patients can ameliorate age-related declines in lung function and decrease overall mortality rates as compared with continued smoking ${ }^{55,56}$ and that several 


\section{Smoking Cessation in Pulmonary Care Subjects}

Table 6. Emergent Themes and Quotes Related to the Questions About Desires and Barriers to Quit Smoking and Increase Levels of Activity

\begin{tabular}{|c|c|}
\hline Emergent Theme & Related Quote \\
\hline Desire to quit & $\begin{array}{l}\text { I wish that one day I wake up and poof, no more, and some days I feel good about myself and I } \\
\text { tell myself I'm too good for that and I do good long as I keep telling myself that. }\end{array}$ \\
\hline Guilt and shame for being a smoker & $\begin{array}{l}\text { And plus I feel ashamed to be out there smoking. you know cause I know it ain't good. } \\
\text {...Just makes me angry to know that I had to smoke. I mean you know, it really does. } \\
\text { [I've got] little great nieces want her aunt to stop so bad, she } 5 \text { years old and she don't even want } \\
\text { me to smoke a cigarette. } \\
\text { Because I wanted to be here so when I could see them two [grandchildren] graduate. I don't want } \\
\text { them to have to grow up and say, "We want Grandma here." I want to show them that I'm going } \\
\text { to be here. } \\
\text { And also my grandchildren, always telling me, "Grandma, didn't the doctor tell you to stop } \\
\text { smoking?" And then they would, and they would take my cigarettes and throw them away so I } \\
\text { ain't had no choice but to [try to] stop. }\end{array}$ \\
\hline $\begin{array}{l}\text { Fear of discomfort and becoming sick } \\
\text { after smoking cessation }\end{array}$ & $\begin{array}{l}\text { I used to try to quit and everything I did try to quit I used to always get toothaches and stuff. } \\
\text { Right. Like I said earlier, my fear is I'm gonna stop, I'm gonna get all these sicknesses, I'm gonna } \\
\text { get worse my cancer's gonna get worse right, I dunno, I really don't. }\end{array}$ \\
\hline $\begin{array}{l}\text { Dislike for pharmacotherapy and adverse } \\
\text { effects }\end{array}$ & $\begin{array}{l}\text { I've tried the gum the gum is hideous and I don't care what nobody says I can't stand it. } \\
\text { It [the patch] had me, uh, dreaming craziness. I only took it about for a week I had to come off of } \\
\text { it you know...weird nightmares that, they say it do that...it had me dreaming weird things. }\end{array}$ \\
\hline $\begin{array}{l}\text { Barriers to engaging in physical activity: } \\
\text { physical activity and/or exercise being } \\
\text { boring and not fun }\end{array}$ & $\begin{array}{l}\text { It makes you tired. } \\
\text { Exercise I don't like that, that's work. } \\
\text { I got arthritis bad in my knees. Bad arthritis. That's my problem. Other than that, I'd be walking } \\
\text { all the time. } \\
\text { I don't like to do it alone cause I get bored. } \\
\text { I can't walk from here to like, you know...say too long...down the hall without being out of breath. } \\
\text { I mean I would love to run, uh, a whole mile I, I wouldn't even make it to the corner, I'll pass out. }\end{array}$ \\
\hline $\begin{array}{l}\text { Importance of, and frequent lack of } \\
\text { access to, social support for smoking } \\
\text { cessation and physical activity }\end{array}$ & $\begin{array}{l}\text { Um what I had when me and my mother was doing [exercising] together was good cause I had a } \\
\text { partner you know this, this is my mother and we, we reaching for something....And then she } \\
\text { slacked off and then I slacked off. } \\
\text { You need like a network to quit, get off of this. I have a, it took a while for me to even learn how } \\
\text { to smoke now it's taking me a while to learn how to get off of cigarettes [group agreement]. }\end{array}$ \\
\hline
\end{tabular}

quit attempts are often necessary to achieve cessation, ${ }^{57}$ there is an imperative to promote smoking cessation in smokers who may not yet meet the criteria for a full-blown COPD diagnosis. Our findings that a COPD diagnosis was predictive of program attendance underscores the point that smokers with earlier stage pulmonary disease may need targeted efforts to increase their awareness that smoking cessation can delay pulmonary disease progression.

Our finding that pulmonary subjects whose mother had a history of cancer were more likely to attend the smoking cessation program adds to our knowledge of familial disease status as a determinant of behavior change. Some theorists conceive familial disease status as a "cue to action." 58,59 For example, having a first degree relative with a history of cancer has been associated with greater intention $^{58}$ and greater success in quitting smoking. ${ }^{60}$ Our data converge with these findings and indicate that pulmonary patients who do not have a familial history of cancer, in particular a mother who had cancer, may need more intensive support to maintain program attendance.

Qualitatively, these data provided some insights into smoking and physical activity beliefs and behaviors among
African-American pulmonary clinic patients. Some of the main themes that emerged from our focus groups included a strong desire to quit and increase levels of physical activity, but several barriers to achieving these behavioral changes were salient, particularly beliefs and fears that these behavior changes could incite poorer health, poor access to pharmacotherapy, and lack of support.

That focus group participants emphatically cited a desire to quit smoking and a belief that increased levels of physical activity were, in general, health-enhancing behaviors, is consistent with population level data showing that at any given time, at least two thirds of smokers intend to quit smoking, ${ }^{61}$ and that the majority of adults wish they could be more active. ${ }^{62}$ Of interest, however, was that when probed to go beyond this abstract perception of what healthy behaviors were, several African-American participants endorsed beliefs that should they quit smoking or become more active, these behavior changes might be detrimental to their personal health. Specifically, several participants talked about close relatives who were diagnosed with cancer after quitting, suggesting that in some way, quitting smoking incited the disease. This concern that 


\section{Smoking Cessation in Pulmonary Care Subjects}

Table 7. Emergent Themes and Quotes Related to Willingness to Use Pharmacotherapy and Technology to Quit Smoking and Increase Physical Activity

\begin{tabular}{|c|c|}
\hline Concepts & Quotes \\
\hline $\begin{array}{l}\text { Mixed feelings toward use of } \\
\text { technology in promoting } \\
\text { cessation }\end{array}$ & $\begin{array}{l}\text { I mean I would like to talk to somebody too [in addition to text-messaging] but I mean, sometimes a } \\
\text { text here and there wouldn't bother me. } \\
\text { Texting me with the info [information]-app [cell phone app] that would help me a lot. } \\
\text { Yeah I'm I guess I'm old school so, phone is one thing but um, texting is not my biggest, you know, } \\
\text { thing. I like to really talk. You, you can get a mixed messages from a text message, so if I'm talking } \\
\text { to you on the phone I think it'd be a better vibe than just a text message. } \\
\text { If it [the texting] was manageable like once a week or something. } \\
\text { I don't read text messages. }\end{array}$ \\
\hline $\begin{array}{l}\text { Endorsement of varenicline } \\
\text { (Chantix) as a cessation aid }\end{array}$ & $\begin{array}{l}\text { The gum was pretty good when I had it. The gum took the edge off, you know, the mints was good. } \\
\text { I'm wearing the patch now and it, it calms me down to smoke that, that that heavy urge that comes... } \\
\text { Everybody I know who's been successful has done it with Chantix which I wish they had offered me in } \\
\text { conjunction with the patch cause I think it would have a...everybody I talk to use Chantix they have } \\
\text { success with it. } \\
\text { And I heard I mean I seen a lot of people that used that [Chantix], and I mean within a month they } \\
\text { were fine like and these people smoked like } 25,30 \text { years and [inaudible] } 30 \text { days they they were done } \\
\text { and } 5 \text { years later they still were not smoking... }\end{array}$ \\
\hline $\begin{array}{l}\text { Difficulty obtaining varenicline } \\
\text { (Chantix) }\end{array}$ & $\begin{array}{l}\text {... You know, they offer me all those things, except for the Chantix and I asked her to write it, she wrote } \\
\text { it, and of course my insurance didn't take it. Um a lot of people really say they quit with Chantix, } \\
\text { um, I would like to really to try the Chantix, and [be] done with the cigarettes. } \\
\text { They said Chantix, that works but I find out my insurance don't pay for that. } \\
\text { But I wish I had just the Chantix just for a starter kit, just between this and that I think I can beat it... } \\
\text { Why can't we get Chantix? I got it because my pulmonary doctor gave me a sample of you know, } 30 \\
\text { day sample and I stopped smoking for } 30 \text { days, but then when I didn't have no more, I got like } \\
\text { paranoid thinking ok well if I don't keep taking these pills I'm gonna start smoking, and that's } \\
\text { exactly what happened. }\end{array}$ \\
\hline
\end{tabular}

quitting actually caused poor health has been reported previously in qualitative studies. ${ }^{63}$ In terms of increased physical activity, several African-American participants spoke of intense fears about breathlessness and bringing on an asthma attack or the like. Collectively, the African-American focus group participants had an underlying belief that smoking cessation and increased physical activity were health goals that were not attainable.

The idea that certain healthful options, such as quitting smoking and being more active, were attainable only by others was particularly apparent in the discussion about smoking cessation treatment and what it would take to facilitate smoking cessation. Several participants became agitated when describing their struggles with acquiring pharmacotherapy, in particular varenicline. Participants noted that whereas 8 weeks of nicotine replacement therapy was recommended, often they could only obtain a 2-week supply from the pulmonary clinic or the state quit line. Lack of Medicare coverage for varenicline was also a point of concern. These concerns are well supported in the literature. Low socioeconomic smokers (such as those who were in the focus groups) have less access to primary care, have less social support to quit, are less likely to have access to pharmacotherapy, and may be less likely to quit because of these reasons. ${ }^{64}$
There are several clinical implications of these findings. First, the finding that COPD diagnosis and maternal cancer history were the strongest predictors of smoking cessation program attendance suggests that increasing perceived risk of COPD among those with lower level poor pulmonary health symptoms and addressing the low levels of knowledge about the benefits of smoking cessation to delay COPD progression are necessary strategies in this population of mostly African-American smokers. Dispelling beliefs that quitting smoking increases risk for disease is another important knowledge-based intervention component. A second implication of these data is that low access to and affordability of pharmacotherapy and more formal smoking cessation therapy is a critical barrier to cessation in this population. This is particularly salient given data showing that once equitable access to pharmacotherapy and cessation treatment is provided, racial and socioeconomic differences in cessation treatment outcome are ameliorated. ${ }^{65}$

The mixed methods approach to address smoking cessation beliefs and engagement in this high-risk population of lower-income, mostly African-American smokers with poor pulmonary health are conceptual and design strengths of this study. Limitations include the relatively low attendance rate to the focus groups, which may exacerbate 


\section{Smoking Cessation in Pulmonary Care Subjects}

participation bias. Focus group participants were also not labelled in terms of their smoking cessation enrollment status; it may have been informative to consider whether the focus group responses varied based on cessation program enrollment status. Another design limitation is in the pulmonary clinic smoking cessation program. In some cases, the first session of the in-house smoking cessation program did not occur until 6 weeks after the patient's appointment with the pulmonologist. This logistical feature of the program was not explicitly considered as a predictor of enrollment and attendance and may have contributed to the relatively low attendance rates observed. Analytic limitations included that absolute values for $\mathrm{FVC}$ and $\mathrm{FEV}_{1}$ in liters were not used in the analysis.

\section{Conclusions}

Despite these limitations, these data provide insight into some of the barriers to smoking cessation among this highrisk African-American population and add to our understanding of how low knowledge about the risks and benefits for smoking cessation and increased activity and poor access to formal cessation treatment (ie, pharmacotherapy), may be priority intervention targets. Physical activity, although endorsed as a desirable behavior, was generally feared by this group and not perceived as a tool to help improve physical activity capacity and maintain pulmonary function. Further work to examine the efficacy of addressing these barriers to smoking cessation and increased physical activity among low-income, AfricanAmerican patients with earlier stage pulmonary disease is urgently needed so that these health-enhancing behaviors will become less extraneous and more achievable.

\section{ACKNOWLEDGMENTS}

We thank Lee Carson for facilitating the focus groups. We also thank all study participants.

\section{REFERENCES}

1. Mannino DM, Homa DM, Akinbami LJ, Ford ES, Redd SC. Chronic obstructive pulmonary disease surveillance: United States, 19712000. MMWR Surveill Summ 2002;51(6):1-16.

2. Centers for Disease Control and Prevention. National vital statistics report. Deaths: final data for 2010. 2013. http://www.cdc.gov/nchs/ data/nvsr/nvsr61/nvsr61_04.pdf. Accessed August 30, 2016.

3. Chatila WM, Wynkoop WA, Vance G, Criner GJ. Smoking patterns in African Americans and whites with advanced COPD. Chest 2004; 125(1):15-21.

4. Foreman MG, Zhang L, Murphy J, Hansel NN, Make B, Hokanson $\mathrm{JE}$, et al. Early-onset chronic obstructive pulmonary disease is associated with female sex, maternal factors, and African American race in the COPDGene Study. Am J Respir Crit Care Med 2011;184(4): 414-420.
5. Hardin M, Silverman EK, Barr RG, Hansel NN, Schroeder JD, Make $\mathrm{BJ}$, et al. The clinical features of the overlap between COPD and asthma. Respir Res 2011;12:127.

6. Rennard S, Decramer M, Calverley PM, Pride NB, Soriano JB, Vermeire PA, Vestbo J. Impact of COPD in North America and Europe in 2000: subjects' perspective of Confronting COPD International Survey. Eur Respir J 2002;20(4):799-805.

7. Dransfield MT, Bailey WC. COPD: racial disparities in susceptibility, treatment, and outcomes. Clin Chest Med 2006;27(3):463-471, vii.

8. Han MK, Curran-Everett D, Dransfield MT, Criner GJ, Zhang L, Murphy JR. Racial differences in quality of life in patients with COPD. Chest 2011;140(5):1169-1176.

9. Troosters T. Physical inactivity in patients with COPD: the next step is. action. Prim Care Respir J 2013;22(4):391-392.

10. Van Remoortel H, Hornikx M, Demeyer H, Langer D, Burtin C, Decramer M, et al. Daily physical activity in subjects with newly diagnosed COPD. Thorax 2013;68(10):962-963.

11. Jamal A, Homa DM, O'Connor E, Babb SD, Caraballo RS, Singh T, et al. Current cigarette smoking among adults: United States, 20052014. MMWR Morb Mortal Wkly Rep 2015;64(44):1233-1240.

12. Trinidad DR, Pérez-Stable EJ, White MM, Emery SL, Messer K. A nationwide analysis of US racial/ethnic disparities in smoking behaviors, smoking cessation, and cessation-related factors. Am J Public Health 2011;101(4):699-706.

13. Benowitz NL, Bernert JT, Caraballo RS, Holiday DB, Wang J. Optimal serum cotinine levels for distinguishing cigarette smokers and nonsmokers within different racial/ethnic groups in the United States between 1999 and 2004. Am J Epidemiol 2009;169(2):236-248.

14. Luo Z, Alvarado GF, Hatsukami DK, Johnson EO, Bierut LJ, Breslau N. Race differences in nicotine dependence in the Collaborative Genetic study of Nicotine Dependence (COGEND). Nicotine Tob Res 2008;10(7):1223-1230.

15. Ahijevych K, Gillespie J. Nicotine dependence and smoking topography among black and white women. Res Nurs Health 1997;20(6): 505-514.

16. Benowitz NL. Smoking cessation trials targeted to racial and economic minority groups. JAMA 2002;288(4):497-499.

17. Wagenknecht LE, Cutter GR, Haley NJ, Sidney S, Manolio TA, Hughes GH, Jacobs DR. Racial differences in serum cotinine levels among smokers in the Coronary Artery Risk Development in (Young) Adults study. Am J Public Health 1990;80(9):1053-1056.

18. Pérez-Stable EJ, Herrera B, Jacob P 3rd, Benowitz NL. Nicotine metabolism and intake in black and white smokers. Jama 1998; 280(2):152-156.

19. Caraballo RS, Giovino GA, Pechacek TF, Mowery PD, Richter PA, Strauss WJ, et al. Racial and ethnic differences in serum cotinine levels of cigarette smokers: Third National Health and Nutrition Examination Survey, 1988-1991. JAMA 1998;280(2):135-139.

20. Fu SS, Kodl MM, Joseph AM, Hatsukami DK, Johnson EO, Breslau $\mathrm{N}$, et al. Racial/ethnic disparities in the use of nicotine replacement therapy and quit ratios in lifetime smokers ages 25 to 44 years. Cancer Epidemiol Biomarkers Prev 2008;17(7):1640-1647.

21. Watz H, Waschki B, Meyer T, Magnussen H. Physical activity in patients with COPD. Eur Respir J 2009;33(2):262-2672.

22. Garcia-Aymerich J, Serra I, Gómez FP, Farrero E, Balcells E, Rodríguez DA, et al. Physical activity and clinical and functional status in COPD. Chest 2009;136(1):62-70.

23. Waschki B, Kirsten A, Holz O, Müller KC, Meyer T, Watz H, Magnussen H. Physical activity is the strongest predictor of all-cause mortality in patients with COPD: a prospective cohort study. Chest 2011;140(2):331-342.

24. Global Initiative for Obstructive Lung Disease. Global Strategy for the Diagnosis, Management and Prevention of Chronic Obstructive 


\section{Smoking Cessation in Pulmonary Care Subjects}

Pulmonary Disease. 2014. http://www.goldcopd.org/uploads/users/ files/GOLD_Report_2014_Jun11.pdf. Accessed October 20, 2014.

25. Lewey J, Choudhry NK. The current state of ethnic and racial disparities in cardiovascular care: lessons from the past and opportunities for the future. Curr Cardiol Rep 2014;16(10):530.

26. Roger VL, Go AS, Lloyd-Jones DM, Benjamin EJ, Berry JD, Borden WB, et al. Heart disease and stroke statistics: 2012 update: a report from the American Heart Association. Circulation 2012;125(1):e2-e220.

27. Troosters T, van der Molen T, Polkey M, Rabinovich RA, Vogiatzis I, Weisman I, Kulich K. Improving physical activity in COPD: towards a new paradigm. Respir Res 2013;14:115.

28. Garcia-Aymerich J, Lange P, Benet M, Schnohr P, Antó JM. Regular physical activity reduces hospital admission and mortality in chronic obstructive pulmonary disease: a population based cohort study. Thorax 2006;61(9):772-778.

29. Garcia-Rio F, Rojo B, Casitas R, Lores V, Madero R, Romero D, et al. Prognostic value of the objective measurement of daily physical activity in patients with COPD. Chest 2012;142(2):338-346.

30. Arne M, Lundin F, Boman G, Janson C, Janson S, Emtner M. Factors associated with good self-rated health and quality of life in subjects with self-reported COPD. Int J Chron Obstruct Pulmon Dis 2011;6:511-519.

31. Esteban C, Quintana JM, Aburto M, Moraza J, Egurrola M, PérezIzquierdo J, et al. Impact of changes in physical activity on healthrelated quality of life among patients with COPD. Eur Respir J 2010;36(2):292-300.

32. Patterson F, Jepson C, Kaufmann V, Rukstalis M, Audrain-McGovern J, Kucharski S, Lerman C. Predictors of attendance in a randomized clinical trial of nicotine replacement therapy with behavioral counseling. Drug Alcohol Depend 2003;72(2):123-131.

33. Jorenby DE, Leischow SJ, Nides MA, Rennard SI, Johnston JA, Hughes AR, et al. A controlled trial of sustained-release bupropion, a nicotine patch, or both for smoking cessation. N Engl J Med 1999;340(9):685-691.

34. Tonstad S, Tønnesen P, Hajek P, Williams KE, Billing CB, Reeves KR, Varenicline Phase 3 Study Group. Effect of maintenance therapy with varenicline on smoking cessation: a randomized controlled trial. JAMA 2006;296(1):64-71.

35. Ahluwalia JS, Harris KJ, Catley D, Okuyemi KS, Mayo MS. Sustained-release bupropion for smoking cessation in African Americans: a randomized controlled trial. JAMA 2002;288(4):468-474.

36. Ahluwalia JS, McNagny SE, Clark WS. Smoking cessation among inner-city African Americans using the nicotine transdermal patch. J Gen Intern Med 1998;13(1):1-8.

37. King A, Sánchez-Johnsen L, Van Orman S, Cao D, Matthews A. A pilot community-based intensive smoking cessation intervention in African Americans: feasibility, acceptability and early outcome indicators. J Natl Med Assoc 2008;100(2):208-217.

38. Matthews AK, Conrad M, Kuhns L, Vargas M, King AC. Project Exhale: preliminary evaluation of a tailored smoking cessation treatment for HIV-positive African American smokers. AIDS Patient Care STDS. 2013;27(1):22-32.

39. Wen KY, Miller SM, Lazev A, Fang Z, Hernandez E. Predictors of smoking cessation counseling adherence in a socioeconomically disadvantaged sample of pregnant women. J Health Care Poor Underserved 2012;23(3):1222-1238.

40. Okuyemi KS, Zheng H, Guo H, Ahluwalia JS. Predictors of adherence to nicotine gum and counseling among African-American light smokers. J Gen Intern Med. 2010;25(9):969-976.

41. Patterson F, Kolman-Taddeo D, Zaslav D, Crinner G, Satti A, editors. Smoking cessation program attendance among pulmonary clinic patients: implications for practice. Denver, Colorado: American Thoracic Society; May 15-20, 2015.
42. Heatherton TF, Kozlowski LT, Frecker RC, Fagerstrom KO. The Fagerström Test for Nicotine Dependence: a revision of the Fagerstrom Tolerance Questionnaire. Br J Addict 1991;86(9):1119-1127.

43. Qaseem A, Wilt TJ, Weinberger SE, Hanania NA, Criner G, van der Molen T, et al. Diagnosis and management of stable chronic obstructive pulmonary disease: a clinical practice guideline update from the American College of Physicians, American College of Chest Physicians, American Thoracic Society, and European Respiratory Society. Ann Intern Med 2011;155(3):179-191.

44. Cooper CB, Dransfield M. Primary care of the patient with chronic obstructive pulmonary disease-part 4: understanding the clinical manifestations of a progressive disease. Am J Med 2008;121(7 Suppl): S33-S45.

45. Woodruff PG, Barr RG, Bleecker E, Christenson SA, Couper D, Curtis JL, et al. Clinical significance of symptoms in smokers with preserved pulmonary function. N Engl J Med 2016;374(19):18111821.

46. den Otter JJ, van Dijk B, van Schayck CP, Molema J, van Weel C. How to avoid underdiagnosed asthma/chronic obstructive pulmonary disease? J Asthma 1998;35(4):381-387.

47. Barreiro TJ, Perillo I. An approach to interpreting spirometry. Am Fam Physician 2004;69(5):1107-1114.

48. Krueger RA, Casey MA. Focus groups: a practical guide for applied research (5th Edition). New Delhi, India: Sage Publications; 2015.

49. Rabiee F. Focus-group interview and data analysis. Proc Nutr Soc 2004;63(4):655-660.

50. Prochaska JJ, Benowitz NL. The past, present, and future of nicotine addiction therapy. Annu Rev Med 2016;67:467-486.

51. Cummings KM, Jette AM, Rosenstock IM. Construct validation of the health belief model. Health Educ Monogr 1978;6(4):394-405.

52. Vestbo J, Sørensen T, Lange P, Brix A, Torre P, Viskum K. Longterm effect of inhaled budesonide in mild and moderate chronic obstructive pulmonary disease: a randomised controlled trial. Lancet 1999;353(9167): 1819-1823.

53. Calverley PM, Anderson JA, Celli B, Ferguson GT, Jenkins C, Jones $\mathrm{PW}$, et al. Salmeterol and fluticasone propionate and survival in chronic obstructive pulmonary disease. N Engl J Med 2007;356(8): 775-789.

54. Melzer AC, Feemster LC, Collins MP, Au DH. Utilization and effectiveness of pharmacotherapy for tobacco use following admission for exacerbation of COPD. J Hosp Med 2016;11(4):257263.

55. Anthonisen NR, Connett JE, Murray RP. Smoking and lung function of Lung Health Study participants after 11 years. Am J Respir Crit Care Med 2002;166(5):675-679.

56. Anthonisen NR, Skeans MA, Wise RA, Manfreda J, Kanner RE, Connett JE, Lung Health Study Research Group. The effects of a smoking cessation intervention on 14.5-year mortality: a randomized clinical trial. Ann Intern Med 2005;142(4):233-239.

57. Borland R, Partos TR, Yong HH, Cummings KM, Hyland A. How much unsuccessful quitting activity is going on among adult smokers? Data from the International Tobacco Control Four Country cohort survey. Addiction 2012;107(3):673-682.

58. Patterson F, Wileyto EP, Segal J, Kurz J, Glanz K, Hanlon A. Intention to quit smoking: role of personal and family member cancer diagnosis. Health Educ Res 2010;25(5):792-802.

59. McBride CM, Puleo E, Pollak KI, Clipp EC, Woolford S, Emmons KM. Understanding the role of cancer worry in creating a "teachable moment" for multiple risk factor reduction. Soc Sci Med 2008;66(3): 790-800.

60. McBride CM, Blocklin M, Lipkus IM, Klein WM, Brandon TH. Patient's lung cancer diagnosis as a cue for relatives' smoking cessation: evaluating the constructs of the teachable moment. Psychooncology 2015. doi:10.1002/pon.4011. 


\section{Smoking Cessation in Pulmonary Care Subjects}

61. United States Department of Health and Human Services. The health consequences of smoking: 50 years of progress: a report of the Surgeon General. Atlanta, Georgia; United States Department of Health and Human Services, Centers for Disease Control and Prevention, National Center for Chronic Disease Prevention and Health Promotion, Office on Smoking and Health. 2014. http://www.cdc.gov/tobacco/data_statistics/sgr/50th-anniversary/ index.htm. Accessed December 11, 2015.

62. Poobalan AS, Aucott LS, Clarke A, Smith WC. Physical activity attitudes, intentions and behaviour among 18-25 year olds: a mixed method study. BMC Public Health 2012;12:640.
63. Sheffer CE, Brackman SL, Cottoms N, Olsen M. Understanding the barriers to use of free, proactive telephone counseling for tobacco dependence. Qual Health Res 2011;21(8):1075-1085.

64. Sheffer C, Brackman S, Lercara C, Cottoms N, Olson M, Panissidi L, et al. When free is not for me: confronting the barriers to use of free quitline telephone counseling for tobacco dependence. Int J Environ Res Public Health 2015;13(1):15. doi:10.3390/ijerph13010015.

65. Fu SS, Burgess DJ, Hatsukami DK, Noorbaloochi S, Clothier BA, Nugent S, van Ryn M. Race and nicotine replacement treatment outcomes among low-income smokers. Am J Prev Med 2008;35(6 Suppl):S442-S448. 